\title{
Hierarchical forms of inequality in reality: in search of regularities and problems of explanation
}

MARTIN HAMPL

Charles University, Faculty of Science, Department of Social Geography and Regional Development, Prague, Czechia

ABSTRACT The paper is devoted to the problems of study of environmental systems, especially to geographic systems. There is a strong focus on a search for regularities in the differentiation of real systems and on a discussion of possible explanatory principles of these regularities. Above all, there is a summary of the results of the research focused in this way at the socio-geographic centre of the Faculty of Science of Charles University. The research is based on the ideas and empirical generalizations of Jaromír Korčák. Eighty years have already passed since Professor Korčák published his study about two basic types of arrangement of mass phenomena in reality: a relative homogeneity of generic systems of elements on the one hand and asymmetric (hierarchical) differentiation of environmental systems on the other.

KEY WORDS hierarchical forms of differentiation - classification of real systems - conditioning of hierarchization - qualitative types of environment

HAMPL, M. (2021): Hierarchical forms of inequality in reality: in search of regularities and problems of explanation. Geografie, 126, 1, 1-28.

https://doi.org/10.37040/geografie2021126010001

Received November 2020, accepted December 2020.

C Česká geografická společnost, z. s., 2021 


\section{Opening discussion}

Differentiation, particularly unequal differentiation, is not only a longstanding and frequent subject of scientific research, but it is also a central issue in social practice. Politicians stress social inequalities in their election promises, describing them as inherited evils that must at the very least be reduced. This ushers in a normative (mainly negative) concept of inequalities and the perceived potential to considerably regulate them, depending on the political regime. As a result, such concepts are primarily ideological in nature, involving disputes between proponents of meritocracy and solidarity in political governance, between left and right, between capitalism and communism, and so forth. Though always at least partly ideologically biased, the social sciences have amassed a great deal of evidence, which has also been empirically corroborated, on the correctness of both principles, which need not rule out each other. They only have opposite effects, and this prompts a search for "compromises" in the effects of both. However, there is extensive evidence that the asymmetric distribution of wealth and power has always existed in all social systems, although there has been considerable variability in the extent of inequality. Hence, social inequalities may be naturally occurring rather than something "deliberately" unfair. This prompts the question of whether inequalities have some general role in reality, whether there are connections between inequalities in nature and society, and whether a system of inequalities means a certain order in the organization of reality. Answering these questions could be the focus of a large-scale research programme, one that, however, social scientists have not yet realized a need for. We do though find frequent studies evaluating or emphasizing the real state of inequalities in the world and individual countries, an example would be the World Development Report produced by the World Bank (2009).

However, despite the marginal interest in studying inequalities in greater depth, specific types or aspects of inequality have been examined. The results of such studies have been at least partly generalized. Significant (even extreme) asymmetric differentiation (represented by a highly right-skewed size distribution) has been empirically established, especially in studies of geographic phenomena. For example, there have been studies on the size differentiation of islands and lakes (Korčák 1938, 1941; Fréchet 1941), glaciers (Schytt 1959), and towns - see the rank-size rule (Auerbach 1913, Zipf 1949). Asymmetric differentiation has also been observed in studies about company size, international conflicts, revenue distribution, and the publication activities of scholars, to name a few (see Novotný 2010 , or Imre, Novotný 2016). Numerous other cases (particularly geographic ones) are mentioned in studies by Korčák $(1941,1973)$, Hampl $(1971,1998,2000)$, and Hampl and Pavlík (1977). We also come across asymmetric differentiation in other, one could say, trivial cases, such as in the relationship between distance and 
transport costs (see localization theories) or in the intensity of migration flows (e.g., Ravenstein 1885). We can undoubtedly expect the same results when it comes to more mundane matters, such as the size distribution of a broken window's shards or of the pieces of a demolished wall. In fact, all such cases offer a simple explanation: if a whole is divided into parts, there is a higher probability of small parts being created than large parts. It has been generally argued that such systems are organized hierarchically: internal parts or units are polarized in terms of their importance (large vs. small, rich vs. poor, etc.), and the larger or more important these parts or units are, the less frequently they occur. Nevertheless, extreme asymmetric differentiation need not always occur due to the presence of specific conditions, which I will discuss below. Therefore, in this paper, the notion of hierarchical organization is understood in a broad, general way. The extent of hierarchization is what is important for distinguishing various types of real systems.

Undoubtedly, the hierarchical organization of inequalities is dependent on many factors that interact in a complicated way. Due to the extraordinary qualitative diversity of wholes and their differing levels of integrity, it would be inadequate to reduce the relationships between wholes and their parts to a single level or a single type. However, earlier studies of inequalities not only failed to explain the processes and factors underlying them, but lacked any attempt at generalization. In this respect, a major shift occurred in the works of Jaromír Korčák (1938, 1941, 1973), who formulated a general conclusion about the existence of two basic types of the size differentiation of mass phenomena in reality and, indirectly, of two fundamental types of real systems. He contested the universality of an unimodal, symmetric (bell-shaped) distribution emphasized by Quetelet (1848). He postulated the existence of (extremely) asymmetric differentiation, characterized, for example, by a hyperbolic curve, which is consistent with the size distributions of geographic phenomena or, in other words, size differentiation of geographic entities (lakes, towns, etc.). Korčák emphasized the essential role of asymmetric differentiation as a first-order regularity, which was extensively corroborated using empirical data assembled by him or adopted from others. Here, a special role was played by the results of analyses of the geographic distribution of many qualitatively diverse phenomena in Czechoslovakia that were conducted as part of work for a statistical geographic atlas, as summarized by Láska (1928). Korčák primarily stressed the global extent of uneven size differentiation, noting that Albert August de Lapparent's hypsometric curve was the first major statistical synthesis in geography in terms of meaning. He also saw in physical-geographic inequalities (and diversity) a crucial condition for inequality in the geographic distribution of various phenomena on the Earth's surface. In this sense, he postulated the primary role of exogenous determining factors for explaining their spatial distribution. He also considered the extent of spatial inequality as a measure reflecting the scope of 
their geographic conditioning. He complemented this clear-cut argument by suggesting that unequal (asymmetric) differentiation could also be observed in nongeographic systems, provided they could be "holistically" evaluated. He gives as examples the size differentiation of all biological individuals or the extent/wealth of generic differentiation within higher taxonomic categories (Korčák 1973, p. 15).

Korčák's findings proved not only the fundamental importance of the topic of differentiation, but also the exceptional scope and complexity of its study. To a considerable extent, this informed the focus of further research, which broadened scope and primary systematization in studying hierarchical organization in reality, and also brought about a major reconsideration of some of his initial ideas. First, this relates to the indispensable distinction between the concept of unequal differentiation on the one hand and "diversity" on the other. Although Korčák did not exactly define these two concepts, his ideas about unequal differentiation accent the quantitative level of inequalities in the (spatial) distribution of studied phenomena, while his thoughts about diversity stress the qualitative wealth, peculiarity, or exceptional character of the relevant "wholes" or the environment. He contrasts the diversity on Earth with the monotony of interstellar space. At the same time, the extreme asymmetry in the size distribution of geographic phenomena, especially inorganic formations (islands, lakes, etc.), is contrasted with the homogeneity of biological species. However, the evolutionary distinction of the shaping of either homogeneous or, on the contrary, asymmetric/heterogeneous distributions is not appropriate. The spatial distribution of mass in the universe is substantially more inequal than the distribution of precipitation, biomass, or populations on the Earth's surface. The generic homogeneity of organisms is primarily analogous to the homogeneity of humankind or types of inorganic elements (types of atoms, molecules, etc.). As a result, it is not an evolutionary but a structural dimension that primarily explains the discrepancies in the organization (the differentiation) of different mass phenomena in the sense of the polarity of homogeneity and hierarchical forms of heterogeneity. This is efficiently expressed in the homogeneity of generic sets of elements (pertaining to inorganic, biological, and also social systems - see Figure 1) as bearers of basic types of qualitative forms of organization on the one hand and a hierarchically differentiated environment (either terrestrial or cosmic) as a space where qualitatively heterogeneous and relatively autonomous phenomena exist on the other. This dimension has been referred to as the complexity principle (Hampl 1971) or the principle of structural complexity (Hampl, 2000). This is a matter of primarily distinguishing the level of qualitative heterogeneity of the respective phenomena and their determining factors in the relevant real systems, including "transitional" cases with limited internal hierarchization (semi-complexes) - see Figures 1 and 2.

Table 1 supplements Figure 1 by presenting the examples of data concerning the four types of indicators of Czech districts that relate to systems of different 


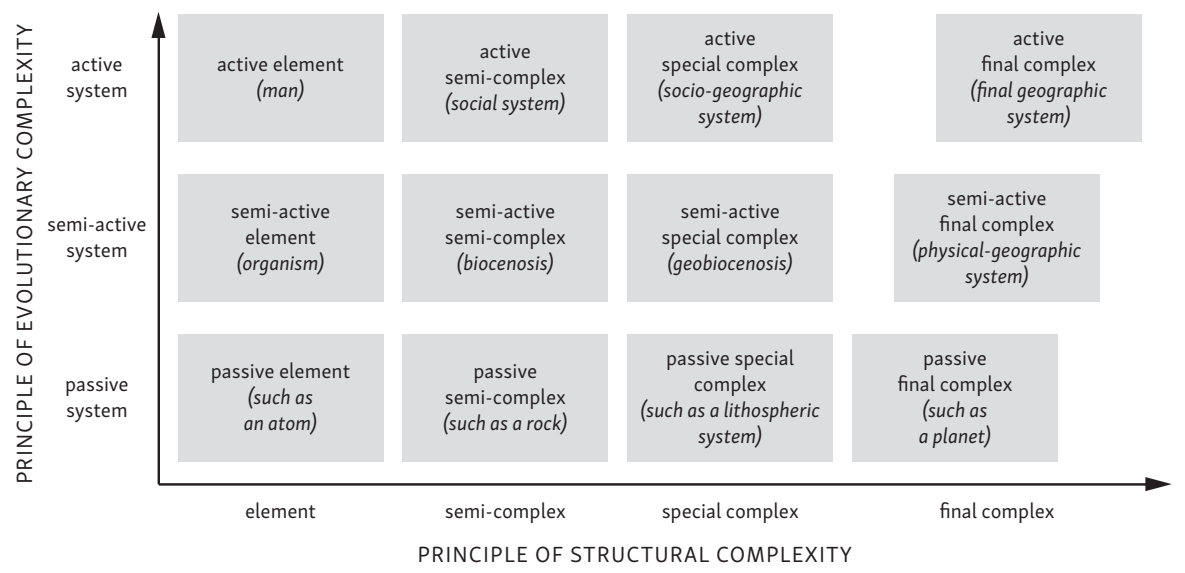

Fig. 1 - Primary classification of real systems. Notes: The arrangement of final complexes expresses both their high structural complexity and evolutional complexity. The distinction of three levels of evolutionary complexity corresponds with the usual division of elements into inorganic-biological-social. However, environmental systems also include phenomena that have diverse evolutionary histories - hence, the choice of denoting passive, semi-active, and active systems. However, distinguishing systems based on the principle of structural complexity is also problematic because here we lack the terminology necessary to do so. In the present article the terms element, semicomplex, special complex, and final complex are used for what was in an earlier study (Hampl 2000) referred to as element, ecosystem, partial environmental system, and final environmental system. Source: Hampl 2000.

structural complexity. This is understandably just an illustrative example and, in this respect, it is once again necessary to refer to the above-quoted studies, which are based on wider and more systematic empirical analyses.

Understandably, the principle of structural complexity covers both qualitative and quantitative (size) aspects of the relationship between a whole and its parts, doing so in a graduated way. However, the extent and complexity of the structuration of reality and the environment itself require size differentiation to be described at various levels of complexity (macro-region - micro-region or local society - global society). This principle of differentiation has been called the rank/scale principle. In comparison with the principle of structural complexity it is of secondary importance. This is because the size, importance, and extent of the rank/scale differentiation changes depending on the complexity of real systems (Hampl 1971, 1994a, 1995, 2000). Nevertheless, the rank/scale differentiation has a dominant role within inorganic reality due to the limited qualitative heterogeneity of inorganic systems. Thus, one can emphasize the combined effect of both these basic principles of differentiation of reality. Both the levels of structural complexity and rank/scale of real systems positively determine the 


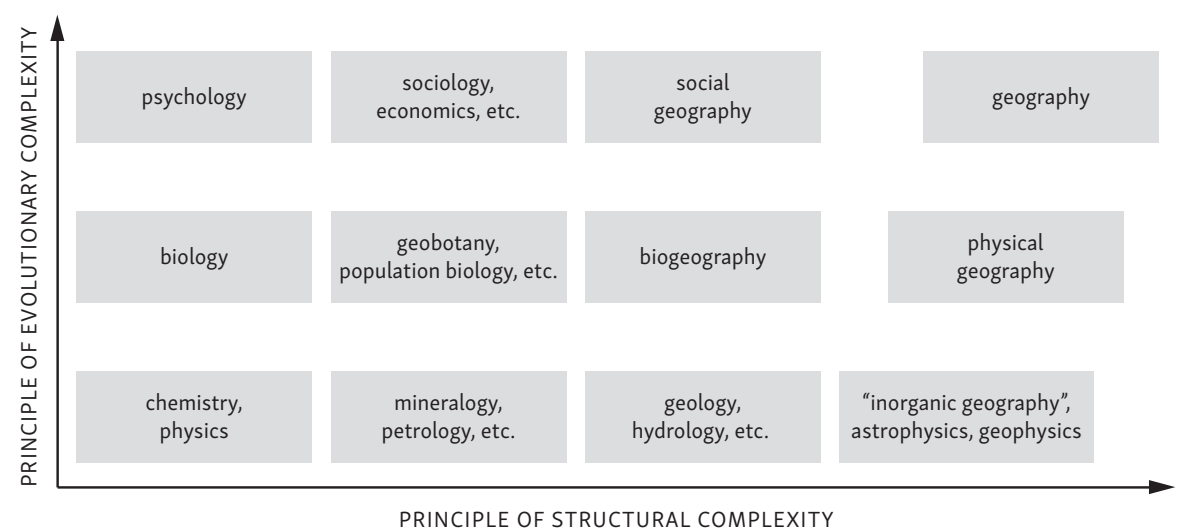

Fig. 2 - Classification of empirical sciences. Notes: Figure 2 is based on principles arising from Figure 1. This selection of scientific disciplines is only illustrative. Along with empirical sciences, it is also necessary to specify at least another three types of sciences: (1) methodological-formal sciences (mathematics, logic, etc.), (2) applied sciences (technical disciplines, management and planning, etc.), and (3) philosophy as the most general science.

extent and hierarchical form "of inequalities". However, one must also stress certain limitations on the validity of hierarchical regularities in the organization of environmental (i.e. supra-elementary) systems. These regularities are only valid for complexes whose elements can be differentiated based on the indices of their size or importance. They similarly apply for the measures of territorial intensity of the occurrence such as population density, precipitation intensity, and so forth. By considering these measures, the differentiation of examined entities (their statistical distribution) may eventually develop into extremely asymmetric form: while no "zero" cases for the population size of settlements or area of lakes, they can appear for the measures of territorial densities or intensities (such as the number of population per square kilometre). For complex systems, one can also distinguish a number of other characteristics that can be considered as structural or structural/generic since they characterize the "generic quality/similarity" of complex wholes. For example, nodal regions are sorts of socio-geographic systems, and therefore they share common characteristics: the internal core-periphery dichotomy, the ensuing functional division, relatively similar proportions in the size of the core and the periphery, the limited variability of their internal integrity, and so forth. They reveal some generic similarity implying that the relative homogeneity with respect to the structural characteristics also exists in the sets of complex systems (for more details, see Hampl 2000).

The principles of structural complexity and rank/scale obviously express the most substantial types of differentiating "wholes into parts" and corresponding 
Table 1 - Variability of Czech districts according to demographic, socioeconomic, and geographic characteristics

\begin{tabular}{|c|c|c|c|c|c|c|c|c|c|c|}
\hline \multirow[t]{2}{*}{ Indicator } & \multicolumn{10}{|c|}{ Frequency according to variation groups } \\
\hline & 1 & 2 & 3 & 4 & 5 & 6 & 7 & 8 & 9 & 10 \\
\hline Number of births per 1,000 inhabitants (1991) & 3 & 1 & 8 & 5 & 20 & 17 & 10 & 7 & 3 & 2 \\
\hline Average wage of employees (1996) & 24 & 26 & 9 & 7 & 6 & 2 & 1 & 1 & 0 & 1 \\
\hline Number of inhabitants per $\mathrm{km}^{2}$ (1996) & 71 & 1 & 0 & 1 & 0 & 1 & 2 & 0 & 0 & 1 \\
\hline Number of inhabitants (1991) & 64 & 9 & 3 & 0 & 0 & 0 & 0 & 0 & 0 & 1 \\
\hline
\end{tabular}

Note: The variation groups were delimited in the size of $10 \%$ of the variation range. The number of districts was 77 ; for the first indicator there were only 76 districts. In a simplified way, the demographic indicator is assumed to illustrate the level of elements (characteristics of people as a biosocial kind), socioeconomic indicator illustrates the level of semi-complexes (related to socioeconomic differentiation of the system), and geographic indicators (i.e. population density and population size) illustrate the level of complexes. The comparison of these indicators represents an easily imaginable example indicating the transition of statistical distributions from the unimodal symmetric distribution (see variation in demographic indicator) through transitional distribution typical for semi-complexes to extremely asymmetrical distribution pertaining to quantities of complex systems. At the same time, this example also provides an intuitive illustration distinguishing differently conditioned attributes using the same set of units in terms of the Czech districts.

Source: Hampl 2000, Table 1, which has been corrected and complemented.

levels of their asymmetric/hierarchical organization. In the broadest sense, one can characterize reality as an aggregate of relatively homogeneous generic sets of elements on the one hand and as a hierarchically differentiated (organized) environment on the other. In fact, the trivial nature of the unequal differentiation of wholes into parts with differing probabilities for the occurrence of small and large parts can also operate in various other more or less specific cases. The asymmetric differentiation of the whole biosphere in terms of the size/weight distribution of individual organisms is undoubtedly of greater consequence (see also Korčák 1973) than the cases of broken windows or walls as mentioned above. To explain these facts, an in-depth understanding of the whole is necessary, especially in terms of what determines the integrity of wholes and the importance of exogenous influences in their shaping, as well as the nature, autonomy, and interactive possibilities of the effect of their parts. The principles of structural complexity and rank/scale enable the identification and systematization of at least main regularities related to structural differentiation of reality, though not their explanation. Hence, in the following I focus on such issues, examining the results of eighty years of research conducted by Jaromír Korčák and his students, including the author of this paper, at the Geographical Institute of the Faculty of Science of Charles University. 


\section{The factors determining the hierarchical form of environmental organization}

How the differentiation of reality is determined cannot be studied at a single level only. It must be done systematically, on multiple levels. Understandably, the most appropriate starting point for discussing crucial terms and objects of study is the general level. Above all, one must distinguish the relationship between the whole and the parts from the relationship between the environment, parts of the environment, and elements. This is essentially a matter of distinguishing the concepts of the whole and the environment, and thus defining various levels of "wholeness". This cannot be achieved with an abstract concept of the whole and of the relationship between the whole and its parts, but only with a specification of this conception related to the "ontologization" of the topic in question. Bearing in mind our limited understanding of reality, let us distinguish just two sorts of the "highest" wholes and their corresponding environment: the universe as the most extensive real system and, within it, the Earth's geosphere which is the qualitatively most developed, and at the same time the most structurally complex real system. Naturally, this distinction involves the separation of a certain part from the universal whole. However, it is appropriate due to the qualitatively exceptional character of the geosphere because it is, given the current state of knowledge, the only sphere in the universe with fully developed internal differentiation with regard to the principle of structural complexity (and understandably also the principle of evolutionary complexity). Nevertheless, when studying the Earth's geosphere, one must consider the effect of the organization of the universe, here essentially restricted to the solar system. Similarly, further examination will single out the geosocial sphere as the geosphere's qualitatively highest subsystem. Hence, the universe/geosphere/geosocial sphere succession is the most substantial evolutionary (qualitative) succession of "final wholes" or environments. At the same time, this succession does not deny, but stresses, evolutionary links. It also expresses the whole-part-part of the part relationship on the highest levels of the "entireness/completeness" of real systems from both quantitative and qualitative viewpoints. From these levels, one can then "descend" to increasingly incomplete parts/subsystems in two specific ways: by following the principle of structural complexity or the rank/scale principle. An aggregation of both dimensions is not possible; however, in the case of the geosphere, the starting point should primarily be levels of quantitatively-qualitative complexity (on the relevant evolutional level) and, within the same basic level of structural complexity, scale differentiation. Evaluating to what extent and how the differentiation of the environment (or "wholes") is organized entails studying the spatial distribution of (substantial, representative) phenomena within this environment. As a result, it should only capture the resulting co-existential arrangement of parts, not the total content of 
a whole. This stresses the holistic approach and the study of the simple or "phenomenal" aspect of the arrangement of wholes, which is consistent with the initial level of knowledge of this topic.

While extreme inequalities in the spatial distribution of phenomena in both cosmic and terrestrial environments can be empirically proven quite easily, we can only speculate when it comes to describing their determining factors. Nonetheless, formulating several simple, explanatory principles is called for. However, such principles would be only non-scientific impulses meant to spark more thorough examinations of these questions in a number of scientific disciplines, specifically in physical and mathematical sciences. The following concepts are an initial attempt at characterizing three crucial factors determining the hierarchical form of differentiation of the final environment and were taken, with some minor modifications, from an earlier study (Hampl 2000, pp. 49-51).

1. First, we can repeat the idea of "the ease of creating minimums and the difficulty of creating maximums", that is, the reality that a whole may be broken into many small parts or only a limited number of larger parts. By aggregating all the divisions of this type, we necessarily arrive at an extremely asymmetric size differentiation of parts within the whole. This can be illustrated by the example of population distribution within a certain regional system when there are no other information (about the attractivity of regions, people's activity, etc.). In such situation, all distributions of a whole (population) among parts (regions) can be assumed equally probable, that is, entropy will be maximized in a statistical sense (Hampl 2000, pp.49-50). Hence, we can refer to this principle as a "statistical" one.

2. The second basic principle takes into account the locational advantage/disadvantage or the "core-periphery" dichotomy. Again, this is a trivial case of asymmetric differentiation in the internal organization of wholes. This is illustrated by the central place theory, which can also be applied spatially. This principle is a "geometrical" one. It has a more significant effect on partial and clearly delineated complex systems.

3. Finally, there is the third, "physical", principle, identified with the scale hierarchy in the effect/application of basic types of interactions. Notable differences in the intensity of interactions on the one hand, and the accumulated effects of only the positive variant of gravitation on the other, bring about the dominance of the "gravitational/hierarchical" organization of natural macro-systems despite the extraordinary weakness of gravitational interactions (Barrow 1991). By contrast, the most important role is played on the level of the micro-world by strong nuclear interactions, which "ensure" the integrity and autonomy of elementary items. Thus, the situation on the Earth's surface is primarily the result of the combined effect of gravitational and electromagnetic interactions. 
In addition to these principles, there are other determining factors that arise from the nature of the "set of parts". In terms of creating hierarchical differentiation, both the frequency and qualitative heterogeneity of the parts are vital. The "qualities" of parts, such as their relative autonomy/integrity or their (external) interactivity, are also essential. Otherwise, the environment would be not only the resulting structure of the whole, but its only, all-encompassing (total) arrangement. However, the second case rules out the physical principle itself, that is, the hierarchical differentiation of basic interactions. Moreover, this differentiation also determines the differences in the extent of integrity and autonomy of the parts as well as the degree of continuity/discontinuity of the environment itself because its "parts" on various scale levels need not be necessarily individualized autonomous wholes.

However, there is one more extremely important underlying principle guiding the hierarchization of partial systems that reflects the organization of their external environment. Its effect can be seen in all real systems, though there are differences in this effect's strength and in the nature of the links holding the system together. Both from the viewpoint of the universe and the geosphere, there is a polarity between an extremely asymmetric/hierarchical arrangement of their "resulting structure" on the one hand and a plurality of generic, relatively homogeneous sets of elements, internally shaped by other principles, on the other. I have already mentioned the vital influence of external conditions in the case of the geosphere, and I will further examine and elaborate on it in another section. In this case, too, we can rightly speak about a principle underlying hierarchization. I have dubbed it the "exogenous principle". However, this is in essence not another principle, but emerges out of the combined effect of the three key principles described above. From the viewpoint of the whole universe, these are "internal" determining factors, but from the viewpoint of all partial systems they are primarily "external" determining factors that shape the primary differentiation of their external environment. Hence, based on current knowledge, one can see the dominant effect of "external" factors in determining hierarchization processes in both complex and semi-complex systems.

However, there are also further differences in the shaping of the cosmic and terrestrial environments. Despite the general similarity in the hierarchization of both environments, these differences must be addressed, at least in simple terms. First, there are enormous differences between the scales and the basic qualities of the two environments. This is reflected by the dominant organization (distribution of the mass in space) of the universe according to the scale principle, the key role of gravitational interactions and the respective hierarchy formed by the polarity of cores (planets, stars etc.) and their peripheries (gravitational spheres). However, there is again the open question of why entire hierarchical (scale) sets of these complexes were created; this is perhaps explained by May's (1972) finding that 
systems divided into blocks are more stable. In many respects, there is a spatial analogy with the central place theory, including the distinction of concentrically arranged core envelopes of different mass density and, thus, also with more limited internal hierarchization (here one can perhaps talk about semi-complexes of a certain kind). In these complexes, internal polarization is several orders greater than in the geosphere. There are extreme inequalities in how mass is distributed in the universe (e.g., the Sun accounts for roughly $98 \%$ of the mass of the whole solar system), compared to terrestrial conditions involving altitude differentiation, biomass and population distribution, and so forth. It should be noted, however, that terrestrial differentiations are also of a clearly pronounced hierarchical type. This comparison suggests a positive connection between the rank/scale of wholes and the degree of their internal differentiation/hierarchization.

The conditions affecting the geosphere's organization may be limited in scale, but their determining factors and structuring are also substantially more complex. Interactions between the main underlying principles of hierarchization, often also encompassing the crucial importance of the influence of the external environment (exogeneity), are combined in two dimensions of "wholeness". There are at least four levels (element, semi-complex, special complex, final complex; see Figures 1 and 2) based on structural complexity. When it comes to levels of rank/ scale, multiple levels can be distinguished and in a generalized way illustrated in by a curve shown in Figure 3 and especially in Figure 4.

We must also consider some general characteristics of the evolution of real systems. The principle of evolutionary complexity has only been assessed statically, with the evolutionary complexity being viewed as a result of evolution, as the qualitative diversification of real systems. However, from this diversification also arises a basic finding about the nature of the evolutionary process: the hierarchical organization of complexes is analogous on all levels of evolutional complexity. The same is true of the relative homogeneity of generic sets of elements. In this sense, the polarity (and the corresponding interaction) of hierarchical differentiation of the environment is constantly being reproduced on the one hand and on the other homogeneity of sorts of elements is evolving. This polarity is a primary source of changes, movement, and development: a repetition of the relatively same elements in various external conditions, in various parts of the environment.

Another critical feature of the evolution of our reality is the progressive direction of changes, the constant creation of new, higher, and more complicated types of elements and complexes. At the same time, this evolutionary process is considerably selective because only a very limited segment of the "higher" is singled out from the extensive "lower". Here, there are substantial differences in the scale of evolutionary successions. Qualitatively higher forms of the environment are spatially "narrowed", while the size of elements is increased. This is depicted in 


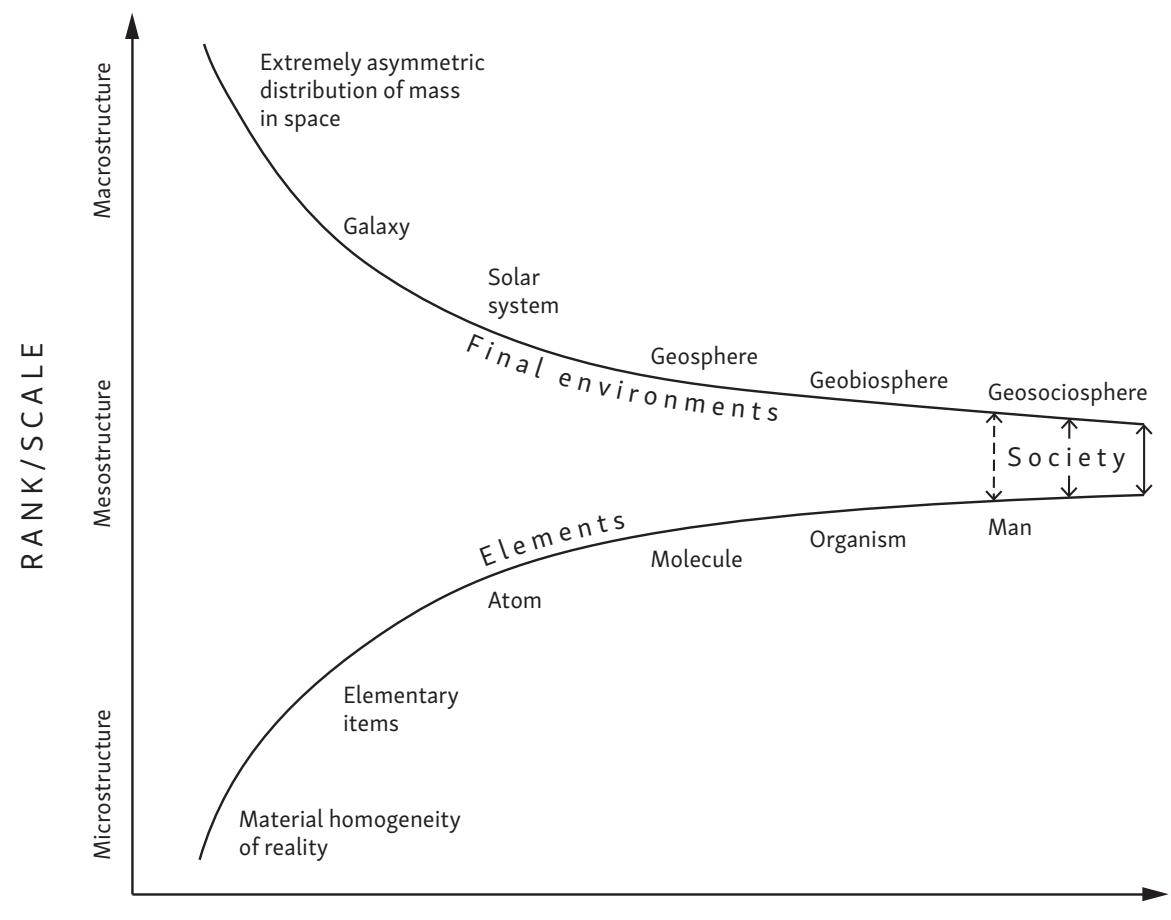

EVOLUTION

Fig. 3 - The evolution of the integral structure of reality. Notes: The space between the two curves is "filled" with partial environmental systems and ecosystems. The given types of systems are of an illustrative nature. The form of curves is designed to express the "transition" from primarily quantitative/scale structuration of inorganic reality to the predominantly qualitative structuration at higher development levels. In the development of society one can see increased interrelatedness of elementary (human kind), ecosystemic (social system) and environmental (geosocietal system) of the organisation of society. Source: Hampl 2000.

Figure 3. Despite the intentionally simplified generalizations, the figure illustrates the selectivity of evolution on the one hand and, in terms of scale, its tendency towards the meso-structure of reality on the other. From a present-day perspective, this tendency culminates in the deeper interconnection of the evolution of active elements and complexes through active semi-complexes (societal systems), which play an integrating role. From the viewpoint of reality in its entirety, the evolutionary process shapes a "secondary" asymmetric differentiation, which from a certain angle, is also hierarchical in nature (as it entails a polarity between the qualitatively lower and higher). As a result, the extreme inequality of the distribution of mass in space is amplified here by the extremely asymmetric qualitative diversity of material systems. 
The hierarchical form of both total arrangements of reality (in terms of the structural and evolutionary complexity) suggests that their determining factors and the corresponding explanatory principles are similar or even identical. This is true, however, only in part and only at an abstract level. It is certainly appropriate to refer to the universal validity of the statistical principle in both sorts of differentiation. However, an in-depth examination reveals significant differences because in the case of evolutionary differentiation, the scarce occurrence of "maximums" appears relatively autonomously both in the sphere of elements and that of supra-elementary wholes and, moreover, in the sphere where elements and the environment interact. Likewise, in these cases the physical principle's effect is not directly related to the evolutionary process but to the distinguishing of the character, determining factors, and level of integrity of elements on the one hand and of complexes on the other. As a result, explaining and understanding the integral evolution of reality is still a matter for future research.

\section{Hierarchical forms of differentiation in the geosphere}

The boundaries of the geosphere delineate the "environment" in which evolutionary higher forms of hierarchization of real systems developed, including their rich structuring in terms of rank/scale or the level of structural complexity of systems. As a result, the extent and forms of hierarchization must be described by combining the three basic classification principles of real systems: the principles of structural complexity, evolutionary complexity, and rank/scale. In the previous section, I demonstrated that the external environment is the primary/ dominant factor shaping the internal organization (differentiation, hierarchization) of partial complexes. In this sense, it is critical to discuss the direction of the effect of the "exogenous principle" in the geographic (terrestrial) environment. First, it will be examined concerning the sets of complex systems (both final and special complexes), where hierarchical organizations appear most significantly in quantitative and qualitative forms.

There are two basic directions in which exogenous factors operate. In terms of evolution, primary/lower evolutionary arrangements influence the organization of systems at the evolutionary secondary/higher levels. In terms of structure, here specified by rank/scale organization, macro-structures affect micro-structures, which means in the case of the environment macro-differentiation determines micro-differentiation. Finally, the priority of the external influences is proven by the already-mentioned differentiation of the geosphere caused by the position and movement of the Earth in relation to the Sun, though further combined with the effect of telluric processes (note that when it comes to the shaping of the geographic environment, consistent with the terminology used in this paper, 
one can refer to both influences as exogenous - unlike the physical-geographic and geological distinction of exogenous and endogenous factors). The combined effect of these exogeneities results in the qualitatively exceptional nature of the geosphere's inorganic components: the atmosphere, lithosphere, and hydrosphere.

Special attention must be paid to the rank/scale dimension that hierarchically structures the environment and the corresponding organization of environmental determinants. It can be to a large extent proven empirically, especially by measuring the relative inequalities in the spatial distribution of different phenomena on individual scale levels: i.e. the spatial inequality within the region of the $\mathrm{N}+1$ scale is assessed according to the differences between the relevant units of the $\mathrm{N}$ scale (internal inequality of the Nth scale units is not taken into account). The observation that the relative inequality tends to decrease with decreasing scale of considered regions was empirically demonstrated in a number of previous studies (e.g. Hampl 1971, 2000). This regularity is expressed in a generalized way in a Figure 4.

There is, however, one exception to this general rule: the distribution of sociogeographic phenomena on micro-regional levels after the onset of modernization processes. However, this important evolutionary aspect will be discussed below. For the natural phenomena, the macro-influences clearly dominate so the determining factors primarily operate in a "top-down" direction. This results in the gradual weakening of hierarchical/asymmetric distribution as the rank/scale is lowered. In fact, at the micro-region scale, natural phenomena are distributed relatively (or partially) homogenously (see also the classical geographical concept of homogeneous regions and common criteria for the spatial definition of such regions). This is, therefore, a rare case of "suppressed hierarchization" of complex systems despite their internal qualitative heterogeneity (completeness). However, what really matters is that this state of affairs is hierarchically determined, namely by a whole system of rank/scale hierarchies or a system of exogenous factors operating in the top-down direction. In this sense macro-differentiation delineates but also restricts micro-differentiation, while the macro-hierarchy suppresses micro-hierarchization. All this proves the prime importance of rank/scale differentiation for the ranking of exogenous determining factors and, at the same time, the prime importance of exogeneities in the shaping of complex systems. Until now, rank/scale differentiation has always been examined on the level of the (resulting) environment or on the level of systems with the highest degree of structural complexity: both final complexes - the geosphere or, in the narrower sense, the sphere of landscape - and special complexes, that is, the basic qualitative subsystems of the geosphere (lithospheric, biogeographic, socio-geographic systems etc.).

The rank/scale differentiation of each these systems is highly developed, and these systems, when combined, characterize evolutionary successions and the 


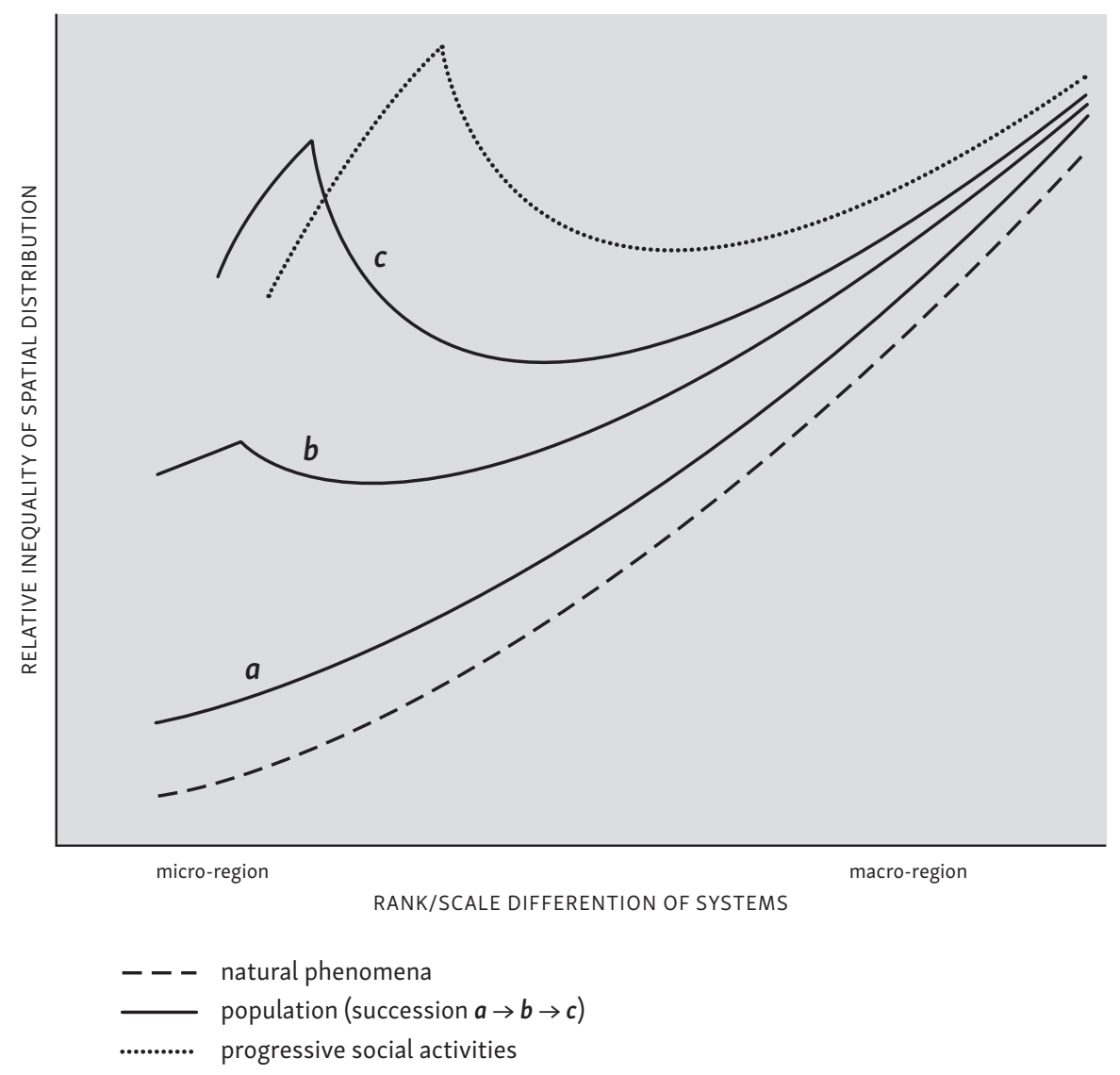

Fig. 4 - Relationship between the relative spatial inequality and rank/scale differentiation. Source: Hampl 2000.

qualitative diversity of the terrestrial environment. The crucial role the external environment plays in influencing such systems results in the weak integrity and autonomy of individual complex systems, their immediate interrelatedness with the final environment, and, therefore, their higher-order "wholeness". Hence, it is correct to emphasize the preponderance of continuity over discontinuity in the differentiation of the environment and the corresponding similarity in the uneven territorial distribution of "all" phenomena (precipitation, biomass, economy, etc.) on the one hand, and the hierarchical differentiation in sizes of individual complex units (lakes, glaciers, towns, etc.), on the other.

Opposing the integral hierarchy of the (entire) environment are elements and their homogeneous generic sets. The distribution of individual elements (atoms, living organisms, etc.) in the environment is "once again" considerably uneven, 
though their internal arrangement is not dominantly determined exogenously, but endogenously. Therefore, these elements can be described as strongly integrated, autonomous, and organic wholes. On this account, reality seems to be - as stated above - primarily a plurality of homogeneous sets of qualitatively diverse elements on the one hand and an integral, hierarchically arranged final complex/ environment on the other. Between these two extremes - between elements and complexes - various "supra-elementary" but limited, complex wholes have emerged; in the classification of real systems they are referred to as semi-complexes. They are diverse formations - rocks, biocenoses, social systems - which have yet to be systematically mapped and are therefore difficult to evaluate. In general, semi-complexes featuring exogenous determining factors are more powerful than endogenous ones, and they have weak integrity and autonomy. As a rule, their rank/scale differentiation is underdeveloped and their also usually do not fully cover the entire terrestrial environment. The highest evolutionary level, on which one can clearly specify the level of elements - semi-complexes - complexes, partly conflicts with these characteristics, as I will examine in the following section.

The discussion of the hierarchization processes organized according to the three crucial principles of differentiation and the classification of real systems can now be closed with a discussion of the interrelationships of these principles that determine how the "external determining factors" operate and changes in time. Above all, there is a certain connection between the principle of evolutionary complexity and the principle of structural complexity, despite their distinct role for the organization of real systems. The tendency of (our) reality to progress is manifested on all levels of complexity - the emergence and development of higher sorts of elements also bring about the shaping of more complicated forms of the environment, the formation of qualitatively higher hierarchies of complex systems. Although this is primarily a qualitative development - i.e. entailing growth in qualitative heterogeneity and the diversity of the "substance of the environment", these changes also have quantitative consequences. Forms of the organization of the environment that are evolutionary higher may have been predominantly determined by lower evolutionary forms, but the higher activity and sensitivity of new/higher phenomena determined not only their higher adaptability to the external environment, but also their "amplifying" response. This is reflected in a certain regularity that has been empirically proven: within systems of the same rank/scale, the relative inequalities in the distribution of phenomena increase in relation to their evolutionary complexity. For example, relative differences in altitude are less pronounced than the inequality in the distribution of biomass, let alone the inequality in population distribution. Even greater spatial inequalities occur in the distribution of the economic activities and, above all, of quaternary economic activities (leading public and private institutions, research and development, etc.). Nevertheless, qualitative differences are more important 
than the described "quantitative differences". In general, the former can be characterized as the gradual enhancement of the important role played by endogenous factors determining the hierarchization of complex systems. The most substantial (though still specific) proof is the qualitative transformation of forms of rank/ scale differentiation of complex and semi-complex systems encompassing social phenomena (see Figure 4). While in the natural world, endogenous factors only have a secondary influence on the creation of supra-elementary systems, internal sources of integration and hierarchization are increasingly important for the organization of social and socio-geographic systems. At least to a limited extent, the importance of endogenous factors outweighs exogenous factors affecting the organization of socio-geographic and, in particular, social systems at lower scales.

\section{The organization of the geosocial sphere}

Naturally, the geosocial sphere as the highest subsystem of the geosphere in terms of its evolutionary complexity is also characterized by the most advanced forms of hierarchical organization in terms of qualitative differentiation. This is, above all, a consequence of society's extraordinary evolutionary dynamism, its environmental arrangement, and the corresponding transformation of hierarchical structures. The ability of people - the qualitatively highest elements - to act is of crucial importance, not only on the individual level, but, above all, on the group level, in cases of both competitive and cooperative interactions. Unlike in the natural world, where the deterministic external influences dominate, social organization (including its external responses) is vitally shaped by the sophisticated mechanisms of competition and cooperation. Cooperation - both the social and geographical division of labour - is strengthened by the competition between society and nature. All this enhances and intensifies the endogenous sources of hierarchization that complement and in some cases overpower or even replace exogenous sources. However, despite the qualitative complexity and evolutionary dynamism of society, society is clearly structured following the structural complexity principle: relative homogeneity of humankind (elements) - rather limited hierarchization of social systems (semi-complexes) - the distinctive hierarchization of socio-geographic systems primarily determined by interactions between society and the natural environment (complexes on both the special and final levels). For a detailed discussion of this structuration, see Hampl 2000 (see the figure and ensuing text on p.67).

To conduct a detailed assessment of the hierarchic forms of organization, complex (socio-geographic) systems should be examined separately from semicomplex (social) systems. These two types of systems differ in their links to the differentiation of natural environment which tend to be "immediate" for complex 
(socio-geographic) systems but "intermediate" for semi-complex (social) systems. The complex systems depend on the larger set of influencing factors. A synthetic depiction of the hierarchical organization of socio-geographic systems is presented in Figure 4, which characterizes the evolution of rank/scale differentiation in the distribution of social and natural phenomena. Although the scope of empirical analyses upon which the generalization presented in this figure is still rather limited (see Hampl 1971, 2000, 2017), these partially hypothetical findings suggest an initial explanation of the state of affairs, especially of how socio-geographic hierarchies evolve:

1. The initial organization of socio-geographic differentiation used to correspond to the organization of physical-geographic differentiation. In the long run, this correspondence was preserved, basically throughout the preindustrial era. Hence, exogenous determining factors dominated, while the somewhat higher degree of the inequal geographical distribution of social phenomena in comparison to that of natural phenomena can be primarily explained by the higher sensitivity of people and communities to inequalities in the external environment.

2. The increase of society's capabilities to grow and the opportunities society could provide, the pace of which sped up in the industrial period, enabled the overcoming of environmental determinism on the one hand and the strengthening and widening of the endogenous (competitive and cooperative) mechanisms shaping socio-geographic hierarchies, on the other. This did not result only in the mere overcoming of the "inequalities of nature", but also in "complementing" them with new sources of inequalities and, in sum, the amplification of inequalities.

3. These tendencies are highly differentiated, not only in the sense of evolutionary acceleration, but also in the sense of rank/scale: the lower the rank/ scale, the more intensely endogenous determining factors replace exogeneous ones. This understandably reflects the differing difficulty of overcoming the power of natural determinants at different scales as the inequality rises along with rank/scale. This also results in the gradual deepening of the duality of physical-geographic and socio-geographic rank/scale differentiation from the bottom up (see also Figure 4). These facts lead to a critical conclusion about the concurrence of evolutionary and rank/scale differentiation in the relationship between society and the natural environment: the autonomy/endogeneity of hierarchization increases both in the process of evolution and in relation to the lowering scale of socio-geographic systems.

As a result, the factors determining the forming of the hierarchical organization of socio-geographic systems expanded significantly in the process of evolution. 
The primary determining factors and their aggregate expression in the form of exogenous conditions were preserved, but unlike natural environmental systems, or the natural environment as a whole, their originally dominant influence was weakened. This was caused not only by the ability of technologically advancing society to overcome constraints of nature, but, above all, by the growing importance of endogenous factors in new and more efficient forms of society's geographic organization or the spatial division of labour. These factors primarily resulted in the spatial concentration of the population, the economy, and political power, and, by extension, in the primary integration of social forces. This also led to the more efficient use of natural resources and the development of the spatial and social division of labour. In this sense, spatial concentration is a highly complex process that provides benefits/advancement in all basic social spheres. Economic benefits are primarily associated with the expansion of mass production as well as the lower costs of constructing and operating technical and social infrastructure. There are also social benefits - better conditions for communication and education - and political effects - the creation of the identity of territorial communities, mainly represented by centres at each spatial level (local, regional, national). All these processes positively influenced each other, having synergistic effects that led towards concentration. This development logically resulted in a hierarchy of "parts" (settlements, regions, etc.) and, by extension, the core-periphery dichotomy. The created and deepened inequalities had a largely positive influence on the functioning and development of socio-geographic systems, or corresponding spatial communities. In fact, the core's dominance was indispensable for the integrity of these systems, and the core-periphery dichotomy created the basis for the (spatial) division of functions in these systems (the analogous urban-rural dichotomy emerged). In the formation of internally polarized regions, the "geometrical" principle, or the principle of locational benefit, played a specific but vital role. The effects of this principle were modified (e.g., distances were relativized by the quality of communications) by endogenously determined processes.

The "spread" of this evolution was realized in two directions. First, a scale shift occurred, from the micro-regional towards meso-regional levels (especially within forming nation-states) and, to a limited extent, macro-regional levels. This corresponds with the different influence of physical-geographic conditions and the influence of the distance factor itself because as scale/rank increases, concentration processes become less intense. The second direction of spread was from economically advanced systems to those systems lagging behind on national levels and eventually on supranational levels as well. Both types of spread are essentially processes of geographic diffusion. In the former, the diffusion is "vertical", and in the latter, "horizontal" (hierarchical forms of diffusion are also often distinguished from contagious forms of diffusion; Hägerstrand 1967). When it comes to the spread of changes or the course of evolution, a major role is played by the hierarchical 
organization of the geographic environment, not only in the spread of changes in socio-geographic systems (e.g., the diffusion of the concentration process in the industrial period in the former Czechoslovakia; Hampl 1994b) but also of other changes, including demographic ones (e.g., Fialová, Pavlík, Vereš 1990).

In the development of socio-geographic systems, not only were progressive changes disseminated, but, above all, the concentration process itself underwent a qualitative transformation. Here, the most substantial role was played by the gradual stabilization of the high level of inequality/hierarchization in the spatial distribution of phenomena and also the growing differences in the importance of individual functions. As a general rule, functions become spatially concentrated at different rates based on their progressivity or importance. Population is less concentrated than job opportunities, and jobs are most concentrated in the quaternary sector, that is, management and innovation positions. Hence, the main centres become more dominant no longer due to growing populations, but thanks to their increasing influence in the socio-geographic system (see also Hampl 2000, p. 74, Figure 11).

A gradual hierarchization within social (semi-complex) systems is well-known fact corroborated by historical evidence. The frequency of military conflicts between nations/states or the "perpetual" fight for power and economic dominance between social groups or family clans within individual societies prove the crucial role of endogenous "competitive" hierarchization processes. The resulting hierarchies in fact led to the deformation of the competitive environment, to competition between uneven parts. Thus, the power elite gained control over the "majority". In many ways, external natural determining factors were replaced by internal, social, or political and economic factors. The "bottom-up" expansion of competitive processes has only occurred in modern stages of development, along with the opening up of society, democratization, and so forth. This is connected with the later development of cooperative processes whose role was limited to the social division of labour in the "production of economic value", but not in the "distribution of the value" between social groups or nations. The importance of endogenous processes for the creation and the reproduction of the hierarchy of social systems and, to a limited extent, socio-geographic systems as well - proves the general tendency towards hierarchization in supra-elementary (environmental) systems, such as societies. Although the elements of these systems are of the same kind, their pluralism, autonomy, and above all activity or vitality are sufficient sources for competitive interactions and the ensuing hierarchization of the "internal societal environment". Nevertheless, exogenous factors have an influence, too, and in the initial stages of a society's development they determine the creation of inequalities and unevenness between spatial communities. Differing natural and locational conditions determined differences in community size and community wealth. The subsequent endogenous processes built upon the already created 
primary social differentiation of the environment. Understandably, interactions between society and nature were the basis for more than just the development of the spatial, and hence social, division of labour, which led to further diversification (specialization) among people and groups. However, these factors had different effects not only on the development process, but also on the rank/scale of systems. This situation resembles that of socio-geographic systems: with increasing scale, the impact of exogenous factors rises.

However, the vital effect of endogenous processes on the internal organization of social systems was not limited to the shaping of their hierarchies. Human activities have naturally led to antihierarchical tendencies, whose determining factors correspond with the relative generic homogeneity of people and their efforts to diminish inequalities in society. Although from a historical perspective, heterogenization/hierarchization processes clearly dominate, they always had certain limitations. Hence, the distribution of power and wealth among people, families, and social groups is not "fully" asymmetric, but, especially at lower levels, inequality has been limited: the poorest and powerless do not comprise the majority. In this sense, "transitional distribution" characterizes the differentiation within a society, also in a statistical sense. This type of distribution is a compromise between the homogeneity of humankind and the (extreme) inequalities presented by external factors, the whole environment.

The interaction of the generic homogeneity of people and the heterogeneity of the external environment, with the latter enhanced by competitive mechanisms, determines the creation of social inequalities. However, the degree of these inequalities differs greatly from phenomenon to phenomenon or from feature to feature. Moreover, they can change in the process of development convergent and divergent tendencies often alternate. In general, we can speak of the gradual overcoming of the "major discrepancies" between people related to satisfying their basic needs (food, clothing), and later their secondary needs (education, car ownership), and so forth. However, when it comes to the most important matters, such as people's shares in wealth and power, inequality/hierarchization has almost always been extraordinarily high, causing deep social tensions and even social unrest. In fact, since quantifying these inequalities is problematic, the objective state of affairs and, above all, evolutionary tendencies cannot be reliably described. There are certainly fundamental differences in assets ownership and real consumption among people, families, and social groups; one can hardly compare the distribution of wealth in slavery-based empires and modern societies; it is unclear how to "divide" public resources between private entities; and so forth. Nevertheless, there is no question that there have always been such extreme inequalities and that they will always trigger social tension. However, these inequalities can be overcome through the creation of institutions and mechanisms that can find acceptable compromises between the principles 
of meritocracy and solidarity, between heritage and current needs, between the integrity of society and free activities of individuals. It is, nevertheless, the heritage of long-term, historical development that causes the most serious and extreme inequality in the distribution of wealth and power between nations, states, and entire civilizations in the modern world. The dominance of endogenous sources of development, together of geographic isolation of large social entities, resulted in their pronounced hierarchization, which considerably differed from the differentiation of these entities according to their size (e.g. population size). Therefore, the present-day global system is hierarchically organized on macro-levels in two ways. Size/population differences between states or civilizations are primarily caused by exogenous factors, reflecting primarily complex/socio-geographic hierarchization. By contrast, unequal socioeconomic development of these entities is largely the result of endogenous social factors, reflecting primarily semi-complex/ social hierarchization. In fact, the activation and subsequent amplification of the socioeconomic differentiation occurred "subsequently", as the world gradually interconnected (see also Hampl 2014).

When the development of the hierarchical organization of social and sociogeographic systems is evaluated, one can clearly see basic qualitative transformations in the factors determining these arrangements in comparison with the natural environment. There is obvious correspondence between evolutionary tendencies at the level of complexes and semi-complexes on the one hand and the reproduction of their structural differences on the other. The most important characteristics of the integral type can be summed up in the following points.

1. Social development leads to the gradual weakening of the role that exogenous factors have on hierarchization, though this weakening is only relative and differs depending on the level of structural complexity, rank/scale, and the developmental maturity of systems. A major role is played by the fact that exogenous and endogenous factors have similar effects, which proves the general validity of hierarchization processes in the shaping of environmental systems in both nature and society. The enhancement of the role of endogenous conditioning is also connected with the formation of qualitatively higher mechanisms of hierarchization. These are specifically competitive and cooperative mechanisms whose importance in the creation of the natural environment is marginal. In addition, endogenous processes directly determine the development of the spatial and social division of labour, which "ensures" a substantially higher degree of integrity and the organic nature of social environmental wholes.

2. Similar to the natural environment, rank/scale differentiation is important in societal complexes and semi-complexes. This type of differentiation also has a decisive effect on the development and enhancement of the role of endogenous hierarchization processes because their "liberation" from natural 
determinism is gradual, going from micro-levels to higher-order levels, on which natural differences are larger and more difficult to surmount. In this sense, one can stress the correspondence of scale and evolutionary differentiation: the effect of exogenous factors decreases in relation to the lowering of both the scale level and the degree of development of social environmental systems. At the same time, endogenous hierarchization tendencies are also major actors, primarily on lower-scale orders in these systems. On account of this, the uniform integral hierarchy of the natural environment is transformed into a "hierarchy of hierarchies", into an overall hierarchy of sub-hierarchies whose conditioning factors are arranged not only from the top down, but also from the bottom up!

3. The above characterized developmental tendencies, including the development of rank/scale differentiation, are basically the same for both the internal (social) and external (geographic) environmental organization of societies. However, there are always also substantial differences reflecting the varying structural complexity of social and socio-geographic systems. While the geographical distribution of social phenomena is primarily the result of interactions between society and the natural environment, internal social conditions are only an intermediate consequence of these interactions. As a general rule, the inequalities/hierarchies of (complex) socio-geographic systems are greater than those of (semi-complex) social systems, but when it comes to the importance/influence of endogenous factors, the reverse is true. At least from the viewpoint of the present-day-world, these differences have the most important consequence in the form of the creation of the dual global hierarchization of state and supra-state systems: size (population), primarily determined exogenously and geographically, and "qualitative development maturity", primarily determined endogenously and socially. Despite very sensitive reactions to this duality in political and public opinion, an optimistic outlook for the future is justified. They can be corroborated by a great deal of empirical evidence about the gradual and partial, though belated, bridging of the major gaps between poor and rich regions, the urban and the rural, and social groups due to the existence of "anti-hierarchization" forces and interests, leading towards the preservation of the integrity of the humankind and subsequently of societies, too. This is consistent with the alternation between divergent and convergent tendencies in societal development as well as scale shifts in the polarization of rich and poor units. This is suggested even by the latest tendencies in changes in the global distribution of wealth (for more details, see Hampl 2014). 


\section{Final remarks}

The main objective of this paper is to prove that hierarchical forms of the organization of environmental systems are generally valid both in natural and social reality. One can similarly stress the existence of regularities of the hierarchical type as the most substantial regularities in the differentiation of reality. Environmental systems essentially constitute spatially and ecologically interconnected or "grouped" sub-phenomena or elements that make up part of the total environment. Unlike elements (atoms, organisms, etc.), their integrity is weak, while, by contrast, their integration into the total environment is profound, which is also consistent with the extraordinary importance of their conditioning by external factors. Based on the results of a long-term study conducted by Jaromír Korčák and the author of this study, it was possible to arrange knowledge about hierarchical organizations to form generalizations that capture not only the total character of the differentiation of the environment, but also its basic structuration according to the three main principles: the level of structural complexity, rank/scale, and evolutionary complexity. However, this topic is extremely complicated, calling for extensive further research focused on the systematic elaboration and specification of the presented "merely general" ideas about the types of hierarchies and the mechanisms that shape them. Nevertheless, my attempt to generalize this knowledge may serve as an initial framework and benchmark for further research efforts.

Environmental systems are "final wholes", and hence holistic approaches must be used to study them. Hitherto developments in science may have unambiguously proven the benefits of reductionist approaches, but they must be applied differently depending on what is being studied. The reductionism is particularly problematic for studying environmental systems, especially those involving social phenomena. In fact, reductionism may even produce misleading results due to the abundance, diversity, and, above all, the combined effects of determining factors on the one hand and the crucial role of exogenous conditions on the other. Both approaches do not cancel each other out; they complement each other. They should both be used to take advantage of the opportunities they offer. In the case of a holistically focused study of environmental systems, it is important to learn about the state and development of complex systems, whose hierarchical organization cannot be reduced to the subsystems comprised of the individual parts of these systems. This is exemplified, in particular, by large social formations such as states or civilizations and their global power structures. However, there are many hierarchically arranged sets of complex systems - as demonstrated in this study - and therefore, we can generalize about their hierarchical formation and define their general typologies and evolutionary successions. Another study distinguished six basic types of hierarchical systems on the basis of a combination of two viewpoints: evolutionary (natural - primary and secondary - societal) and 


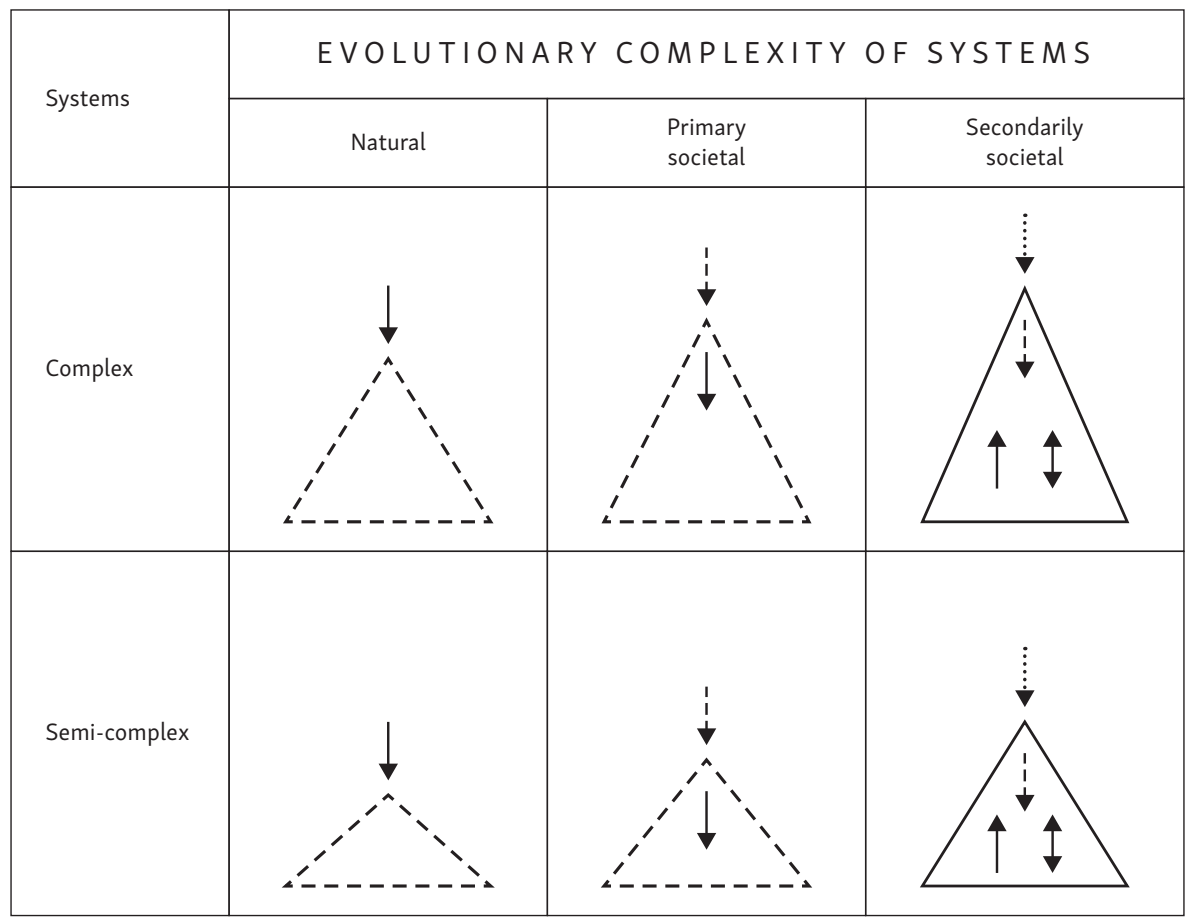

Fig. 5 - Classification of real hierarchical systems. Notes: The triangles symbolize hierarchical structures. The height of the triangle is consistent with the level of hierarchization and inequality of the differentiation. Dashed lines indicate lower integrity (autonomy) of natural and primary societal complexes and semi-complexes due to the marginal importance of endogenous conditioning. Exogenous and endogenous determining factors as well as their relative force are also distinguished. Determining factors are indicated by downwards-facing arrows, competitive factors by upwards-facing arrows, and cooperative factors by side-to-side arrows. Their order is in keeping with the evolutionary complexity of systems: there is a vital stress on the role of endogenous factors in secondary societal complexes (socio-geographic systems) and, above all, semi-complexes (social systems). However, it is only pronounced on lower-scale levels. Source: Hampl 2000.

structural complexity (semi-complex and complex). The considered characteristics were as follows: degree of inequalities/hierarchization, level of integrity, and, in particular, the varying importance of deterministic, competitive, and cooperative mechanisms when a hierarchy is created (see Fig. 5).

However, the distinction of six types of hierarchies of systems indicated in Figure 5 only focused on the evaluation of the terrestrial part of the geosphere. Even so, it was simplifying out of necessity because it did not take into account the importance of rank/scale differentiation, which was reduced to a single level to summarily capture differences in degrees of inequalities and integrity, and the 
qualitative nature of hierarchization mechanisms. Of course, if this typology was widened, especially to include astrophysical systems, the rank/scale dimension would have to be considered. Although to produce such a widened typology of hierarchies and systems would certainly be desirable, it would also be difficult due to our currently insufficient knowledge, especially of natural semi-complexes. Therefore, the following points summarize the basic characteristics of the three evaluated types of "environment". These characteristics suggest not only the main differences in hierarchical forms of environmental systems, but, above all, they demonstrate the general validity of hierarchical regularities in the arrangement of all qualitative types of environment:

1. The cosmic environment is extreme in the quantitative sense, in terms of both the dimensions of environmental systems and inequalities in the spatial distribution of mass. With regard to the internal organization of cosmic wholes, the rank/scale dimension clearly dominates, while differences in the level of structural complexity or evolutionary complexity occur less often. The above-characterized "internal" primary (statistical, geometrical, and physical) principles are the basic factors determining hierarchical formations. However, they interact and shape the rank/scale differentiation of the universe as solely exogenous factors "from above". Nevertheless, these observations stem only from the author's non-scientific examination, based on a comparison of phenomenal features of three qualitatively different environments.

2. Differentiation in the natural environment within the geosphere, specifically in its terrestrial part, does not reach extreme levels of inequality, but it harbours a fundamentally higher qualitative/typological diversity of both semi-complex and complex systems. The dominant role here is played by exogenous factors organized according to both rank/scale and order of evolutionary succession. This also results in the maturity of differentiation from the viewpoint of the structural complexity principle. Nevertheless, endogenously determined hierarchization processes are of only limited importance, also in the case of the geo-biosphere.

3. The hierarchical organization of the geosocial sphere is qualitatively distinct, particular if considering its development. It is characterized by the development of competitive and cooperative endogenous hierarchization mechanisms, which gradually restrict (but do not eliminate) the influence of exogenous factors, though in many respects, they amplify their influence, although this depends on the developmental maturity and scale of the systems. Despite the evolutionary concurrence of changes in complex (socio-geographic) and semicomplex (social) systems, there is also a major distinction between them: the relative separation of the internal (social) and external (geographic) environment of society with a varying degree of the effect of endogenous sources of 
hierarchization. At present, this duality is also marked to a considerable extent by obvious differences in the size and "qualitative maturity" of nation-states and civilizations.

This examination and the above-cited earlier study suggest major facts for studying "total" social problems, in terms not just of scientific knowledge, but, above all, of political decision-making. First, it is necessary to understand and "accept" hierarchical differentiation as a regularity in the organization of society in terms of its external (socio-geographic) and internal (social, political, or economic) structure. Similarly, a hierarchical structure ensures the integrity of systems, a base for the division of functions within them, and the space necessary for developing both competitive and cooperative mechanisms. The perpetuated dichotomy between the rich/powerful and the poor/powerless cannot be overcome by eliminating the hierarchy, but only by qualitatively transforming it or by increasing the role of cooperative mechanisms and perfecting interactions between competitive (market, political competition) and cooperative (division of labour including the appropriate redistribution of outcomes, antimonopoly regulations) mechanisms. As a result, hierarchy is not in conflict with democracy, but democratic institutions and instruments must insist on its qualitative improvement, which should take place in harmony with the "natural" development tendencies of existing hierarchical systems (see the suggested successions in Figure 5).

\section{References}

AUERBACH, F. (1913): Das Gesetz der Bevölkerungskonzentration. Pettermann's Mitteilungen 59: 287-315.

BARROW, J.D. (1991): Theories of Everything. The Quest for Ultimate Explanation. Oxford University Press, Oxford.

FIALOVÁ, L., PAVLÍK, Z., VEREŠ, P. (1990): Fertility decline in Czechoslovakia during the last two centuries. Population Studies, 44: 89-106.

FRÉCHET, M.R. (1941): Sur la loi de répartition de certaines grandeurs géographiques. Journal de la Societé de Statistique de Paris, 82: 114-122.

HÄGERSTRAND, T. (1967): Innovation Diffusion as a Spatial Process. University of Chicago Press, Chicago.

HAMPL, M. (1971): Teorie komplexity a diferenciace světa. Charles University, Prague.

HAMPL, M. (1994a): Environment, Society and Geographical Organization: The Problem of Integral Knowledge. GeoJournal, 32, 191-198.

HAMPL, M. (1994b): Long-term trends in the settlement system. In: Barlow, M., Dostál, P., Hampl, M. (eds): Territory, Society and Administration. The Czech Republic and the Industrial Region of Liberec. University of Amsterdam, Amsterdam, 21-29.

HAMPL, M. (1995): Geographical systems and the order of reality. In: Benko, G.B., Strohmayer, U. (eds): Geography, History and Social Sciences. Kluwer Academic Publishers, Dordrecht, Boston, London, 71-80. 
HAMPL, M. (1998): Realita, společnost a geografická organizace: hledání integrálního řádu. Faculty of Science, Charles University, Prague.

HAMPL, M. (2000): Reality, Society and Geographical/Environmental Organization: Searching for an Integrated Order. Charles University, Faculty of Science, Prague, https://www.natur. cuni.cz/geografie/socialni-geografie-a-regionalni-rozvoj/other/files/hampl-order.

HAMPL, M. (2014): Je nástup konvergenčních tendencí v diferenciaci globálního systému potvrzením obecných představ o vývoji územních a sociálních hierarchií? Geografie, 119, 1, 26-49.

HAMPL, M. (2017): Řádovostně měřítkové uspořádání distribuce geografických jevů: př́iklad obyvatelstva. Informace ČGS 36, 1, 1-19.

HAMPL, M. (2018): Hierarchické formy uspořádání nerovnoměrností v realitě: hledání pravidelností a problémy explanace. Informace České geografické společnosti 37, 1, 1-23.

HAMPL, M., PAVLÍK, Z. (1977): On the nature of demographic and geographic structures. AUC-Geographica 12, 1, 3-23.

IMRE, A.R., NOVOTNÝ, J. (2016): Fractals and the Korcak-law: a history and a correction. The European Physical Journal H, 10, 1, 1-23.

KORČÁK, J. (1938): Deux types fondamentaux de distribution statistique. Comité d'organisation Bulletin de l'Institute Int'l de Statistique XXX-3: 295-299.

KORČÁK, J. (1941): Př́rodní dualita statistického rozložení. Statistický obzor 22, 171-222.

KORČÁK, J. (1973): Geografie obyvatelstva ve statistické syntéze. Charles University, Prague.

LÁSKA, V. (1928): Zpráva o zeměpisném statistickém atlase. Věstník České Akademie věd a umění 37, 61-71.

MAY, R.M. (1972): Will Large Context System be Stable? Nature 238, 413-414.

NOVOTNÝ, J. (2010): Korčákův zákon aneb zajímavá historie přírodní duality statistického rozložení. Informace ČGS 29, 1, 1-12.

QUETELET, A. (1848): Du système social et des lois qui le régissent. Guilloumin et Cie. Paris.

RAVENSTEIN, E.G. (1885): The Laws of Migration. Journal of the Statistical Society of London, $48,2,167-235$.

SCHYTT, V. (1959): The glaciers of Kebnekaise-massif. Geogr. Annaler, 41, 213-227.

World Bank (2009): World development report. Reshaping economic geography, The World Bank, Washington D.C., USA.

ZIPF, G.K. (1949): Human Behavior and the Principle of Least Effort. Addison-Wesley Press, Cambridge, MA.

\section{ACKNOWLEDGEMENTS}

This paper is an extended and modified text of a previously published study in Czech (Hampl 2018). The presentation of the study in English was made possible thanks to the positive approach of the editorial board of the Geografie journal. In this way, it took into account the $80^{\text {th }}$ anniversary of the publication of Jaromír Korčák's classic study (1941) as well as the $50^{\text {th }}$ anniversary of the publication of a book with a theoretical focus by the author of this contribution (Hampl 1971). The author would like to thank Pavel Vereš greatly for translating this study and Nicolas Orsillo and Josef Novotný for its final revisions. 